\title{
Is There a Relationship Between Youth Bullying and Internet Addiction? An Integrative Review
}

\author{
Judith A. Vessey ${ }^{1,2} \cdot$ Rachel L. Difazio ${ }^{3,4} \cdot$ Laura K. Neil $^{5} \cdot$ Anna Dorste $^{6}$
}

Accepted: 3 December 2021

(c) The Author(s), under exclusive licence to Springer Science+Business Media, LLC, part of Springer Nature 2022

\begin{abstract}
Youth bullying is a global public health problem; Internet addiction is on the rise globally among youths. Because the linkage between these behaviors has not been clearly explicated, this integrative review evaluated the relevant empirical evidence. A search of five electronic databases identified 2,761 original citations published between January 2000 and May 2019. After further abstract screening and detailed evaluation of 262 full-text articles, the final sample consisted of 14 prospective descriptive studies representing 10 countries. Review results clearly established that the relationship between bullying and Internet addiction is firmly supported; less is known as to the contribution of gender, age, and other demographic variables, their impact on health outcomes, problematic behaviors, and the role of parental mediation. Inconsistent definitions and instrumentation and lack of sophisticated study designs limited the synthesis of findings. Future research is needed to explicate these relationships, so data-driven interventions can be developed.
\end{abstract}

Keywords Internet addiction · Youth bullying $\cdot$ Cyberbullying $\cdot$ Aggression $\cdot$ Integrative review

Youth bullying remains a major public health problem internationally (Elgar et al., 2015; World Health Organization [WHO], 2012). Composite findings support that approximately one-third of youths across the globe have been victimized by bullying (Elgar et al., 2015; Modecki et al., 2014). Bullying has traditionally been defined as being "exposed, repeatedly and over time, to negative actions on the part of one or more other persons, and he or she has difficulty defending himself or herself" (Olweus, 1993). Although the concept of

Rachel L. Difazio

Rachel.difazio@childrens.harvard.edu

1 William F. Connell School of Nursing, Boston College, Chestnut Hill, MA, USA

2 Medicine Patient Services, Boston Children's Hospital, Boston, MA, USA

3 Department of Orthopedic Surgery and Sports Medicine, Boston Children's Hospital, 300 Longwood Avenue, Boston, MA 02115, USA

4 Department of Orthopedic Surgery, Harvard Medical School, Boston, MA, USA

5 Hematology/Oncology Nursing, Boston Children's Hospital, Boston, MA, USA

6 Medical Library, Boston Children's Hospital, Boston, MA, USA 
bullying had been construed somewhat differently by policy-makers and researcher internationally, common concepts across current definitions include aggression, repetition, power imbalance, intent, and victimization (Gladden et al., 2014; Srabstein \& Leventhal, 2010).

Although bullying prevention has been a global public health initiative for the past 2 decades (Srabstein \& Leventhal, 2010), no significant reduction in youth bullying has been realized (Due \& Holstein, 2008; Elgar et al., 2015; Modecki et al., 2014; U.S. Centers for Disease Control and Prevention [CDC], 2018). One likely explanation for this is the rise of easy online access and its impact on youths' social interactions and psychological well-being as these increase the potential for cyberbullying perpetration and victimization (Livingstone et al., 2016).

Internet usage by today's youths is omnipresent, ranging from completing schoolwork to listening to music, gaming, and socially engaging with peers. While just over half used the Internet sporadically at the turn of the twenty-first century, virtually all of today's youths use it on a daily basis. The digital divide between rich and poor, metropolitan and rural, and across races and ethnicities has all but disappeared (Anderson \& Jiang, 2018). Access to Internet sites is no longer dependent on computer availability. Today between 45 and $95 \%$ of adolescents across the USA, Europe, and Southeast Asia report having their own smartphones with many reporting being online "constantly" and not being able to go more than a day without accessing their smartphone (Anderson \& Jiang, 2018; Mak et al., 2014; Mascheroni \& Ólafsson, 2016; Statistica, 2019). Moreover, the age of smartphone ownership continues to fall, now approximating age 10 years in some countries (Howard, 2017; Influence Central, 2016).

Not only has youth Internet usage increased but so has the complexity of peer interactions through enticing online social media and gaming platforms (Wallace, 2014). These sites are easy to use and have bright graphics and other compelling features. Rooted in variable ratio, partial reinforcement programming, they are designed to encourage users to sustain a high level of connectivity (Wallace, 2014). For example, a user's behavior is reinforced by the number of "likes," "dislikes," "shares," or "comments" an online post receives by others or awards and penalties meted out in online games. Research findings support that online engagement influences a youth's developing sense of self and peer relations, for better or worse (Best et al., 2014; Lemish, 2013; Richards et al., 2015; Shapiro \& Margolin, 2014).

For a subset of youths, online behavior can become compulsive and problematic, leading to disruptive family and peer relationships, physical and mental health problems, and worsening academic performance (Bailin et al., 2014; Gámez-Guadix et al., 2013; Guan \& Subrahmanyam, 2009). This cluster of behaviors is often referred to as Internet addiction (IA) or Internet Addiction Disorder; the term IA will be used throughout this review (Wallace, 2014). Internet addiction among youths has increased exponentially during the COVID-19 pandemic along with interpersonal violence and mental health concerns related to bullying (Fegert et al., 2020; Guessoum et al., 2020; Lin, 2020; Paschke et al., 2021). Simultaneously, indications are that current cyberbullying rates and future susceptibility are on the rise (Jain et al., 2020; Karmakar \& Das, 2020), underscoring concerns regarding the synergic and harmful impact of these behaviors.

Explicating the relationship between youths' risk for engaging in peer bullying and IA is needed to help develop meaningful interventions. This integrative review examines the current state of the science of youth bullying and IA and identifies areas for future research while providing initial implications for practice. 


\section{Methods}

\section{Eligibility Criteria}

The inclusion criteria for studies were as follows: (1) they were original research articles, (2) the study was published in an English language peer-reviewed journal, (3) studies included youths between the ages of 10-22 years old, and (4) the study investigated youth behaviors consistent with bullying and IA. These inclusion criteria were selected as they would capture all papers related to youth bullying and IA. Papers were excluded if the study did not evaluate both bullying and IA.

\section{Search Strategy}

The search strategy was developed by an academic reference librarian in consultation with the research team to comprehensively identify all relevant studies that examined the relationship between youth bullying and IA. The Preferred Reporting Items for Systematic reviews and Meta-analyses (PRISMA) guidelines were used for tracking sources (Moher et al., 2009). Original research articles were systematically sought by searching the following five databases: CINAHL, Embase, PubMed, PsychINFO, and ERIC. The searches included preferred terms for each database relating to bullying and IA, as well as variants of the following main keywords: technology dependency, addiction or overuse, and bullying victimization or perpetration. As the terms bullying and IA have been emerging terms, they are often inconsistently or vaguely defined, varying by the study date, discipline, and country of origin. To address this, specific criteria for both these terms were determined a priori and used in screening articles to determine relevance for this review. These definitional criteria and the components of the definition that were measured in each study can be found in Table 1.

Using the publication date filters for each database, the results were restricted to citations published between 2000 and 2019. This start date correlates with the inception of professional interest in bullying as well as expanding adolescent Internet use (Monks \& Coyne, 2011). Across these 2 decades, significant advancements in online gaming, the advent of social media, and the inception of new Internet platforms (i.e., smart phones, tablets) occurred, allowing trends associated with bullying to be tracked (Islam \& Want, 2014; King, 2002; Van Dijck, 2013). All searches were conducted on May 31, 2019. A targeted, hand search of reference lists of papers meeting our inclusion criteria was also conducted to identify any additional relevant references.

\section{Study Selection}

The search strategy resulted in 3,299 citations. An additional 8 citations were found through ancestry searching leaving a total of 3,307 citations. The final search product was downloaded into Mendeley Reference Manager Software. A deduplication function was then performed using Mendeley citation software, and 546 citations were eliminated, resulting in 2,761 remaining citations for possible inclusion. An additional 2,499 citations were excluded because they were not on topic, not research studies, or not written in English. The remaining 262 abstracts were then subjected to full-text review for eligibility 
品

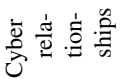

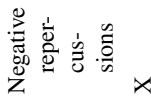

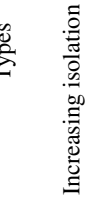

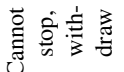

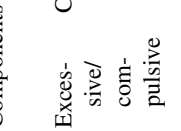

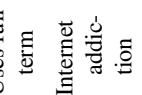

$\frac{\overline{0}}{2}$

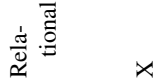

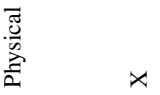

$\frac{\mathscr{d}}{\mathscr{g}}$

.

ڤ.

$x$

$\cdot \frac{1}{2} \cdot \frac{0}{0}$

$x$ 


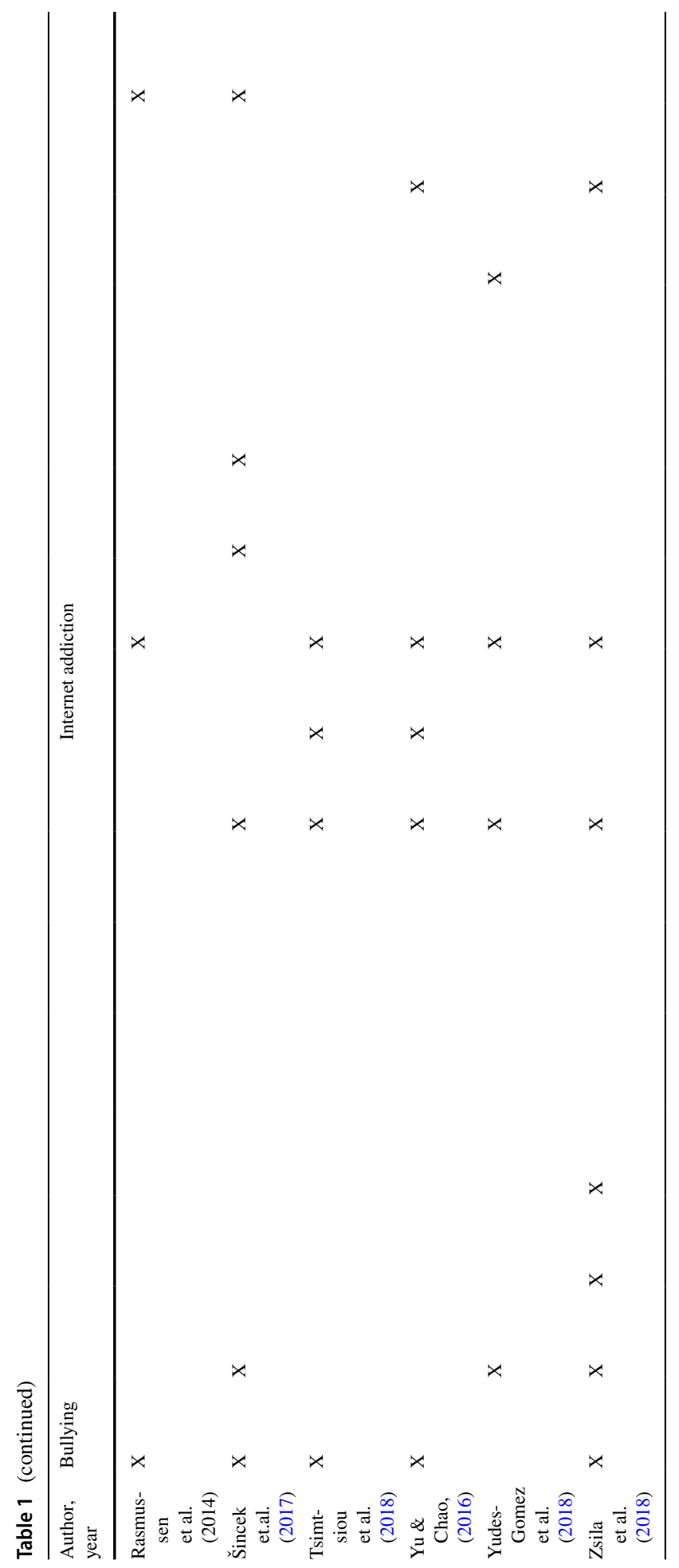


by three research team members. An additional 248 citations were excluded when it was determined that they did not meet the inclusion criteria, leaving 14 articles in the final sample (see Fig. 1).

\section{Data Evaluation}

Data and key information were extracted from each article for evaluation. The level of evidence and the quality of the article were assessed by two raters using the Johns Hopkins Nursing Evidence-Based Practice Rating Scale (JHNEBPS) (Dang \& Dearholt, 2017). Articles were assigned a level of evidence (I-V) based on their study design, ranging from experimental studies being classified as level I and experiential and non-research being classified as level V (Dang \& Dearholt, 2017). The quality rating of the study was based on the level of evidence and ranged from A (high quality) to C (low quality or having major flaws). The quality ratings were completed by two members of the research team. A study with a high-quality rating was consistent, had generalizable results, has an adequate sample size for the study design, ensured adequate control, reported definitive conclusions, and had consistent recommendations based on a literature review, whereas a low-quality study had little evidence with inconsistent results, insufficient sample size for the study

Fig. 1 Identification of studies meeting review criteria

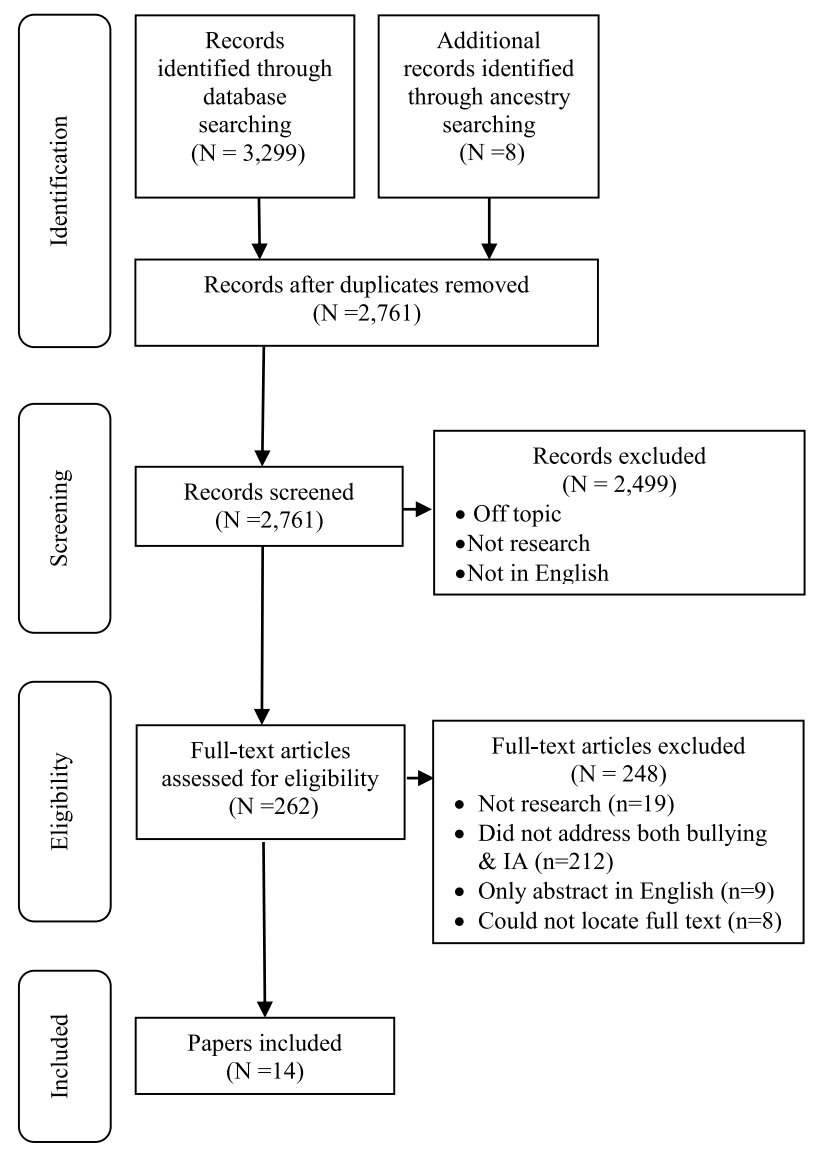


design, and conclusions that could not be drawn (Dang \& Dearholt, 2017). When disagreements among the raters occurred on the quality assessments, the original manuscript and JHNEBPS were consulted and discussed until consensus was reached. If consensus could not be reached through discussion, the entire study team met to discuss the article. The first author served as the final decision-maker.

\section{Results}

The results of this integrated review report on the findings, themes, and key insights from the identified relevant studies (see Table 2). The final sample was comprised of 14 prospective descriptive studies with a total of 39,031 participants, 19,089 males and 19,942 females, ranging in age from 11 to 22 years from ten countries across the globe representing 3 continents with the majority being conducted in Europe. No studies were conducted in Africa, Antarctica, Australia/Oceana, or North America. Of note is that although the timeframe for the search spanned from 2000 to 2019, all of the studies that met the inclusion criteria were published in the last 7 years, supporting the increased recognition of these co-existing behaviors. All studies in this review were level III evidence indicating that they were all non-experimental studies or qualitative studies. The quality of the studies was as follows: high quality $(N=4)$, good quality $(N=8)$, and low quality or major flaws $(N=2)$.

Despite applying tight screening criteria in determining the final sample of articles, the conceptual and operational descriptions of bullying and IA varied widely across studies; only four studies explicitly used both terms (see Table 1). All studies, despite varying quality, were included if they were aligned with the aims of the review.

\section{Prevalence of Co-existing Bullying and IA}

The co-existence of bullying and IA was supported across this entire body of research. The majority $(n=9)$ of the research studies focused solely on cyberbullying, while five studies discussed bullying more broadly. With the exception of cyberbullying, other specific forms of bullying such as physical and relational bullying were not explicated addressed.

It was generally reported that youths with IA had both significantly higher rates of victimization or victimization/perpetration (victim-bullies) from general bullying (Nasaescu et al., 2018; Zsila et al., 2018) and cyberbullying (Chang et al., 2015; Handono et al., 2019; Jung et al., 2014; Nartgün \& Cicioğlu, 2015; Tsimtsiou et al., 2018; Yudes-Gómez et al., 2018; Zsila et al., 2018) than compared to youths without IA. Tsimtsiou et al. reported that cyber-perpetrators were more likely to be victimized within a year's time, further explicating the relationship between victim-perpetrator. Other reports, however, only demonstrated a significant association between IA and bullying perpetration but not victimization (Busch, et al., 2013; Gámez-Guadix et al., 2016; Šincek et al., 2017). Although the association between bullying and IA is clearly established, causal relationships are poorly determined. Little longitudinal data is also available, although Gámez-Guadix et al. demonstrated that IA increased cyberbullying perpetration across two measurement points 6 months apart.

Different forms of IA were captured in the instruments used across these studies. These included excessive screen time (Busch et al., 2013; Kircaburun \& Baştuğ, 2016; Nartgün \& Cicioğlu, 2015; Tsimtsiou et al., 2018; Yu \& Chao, 2016); extensive or risky social 


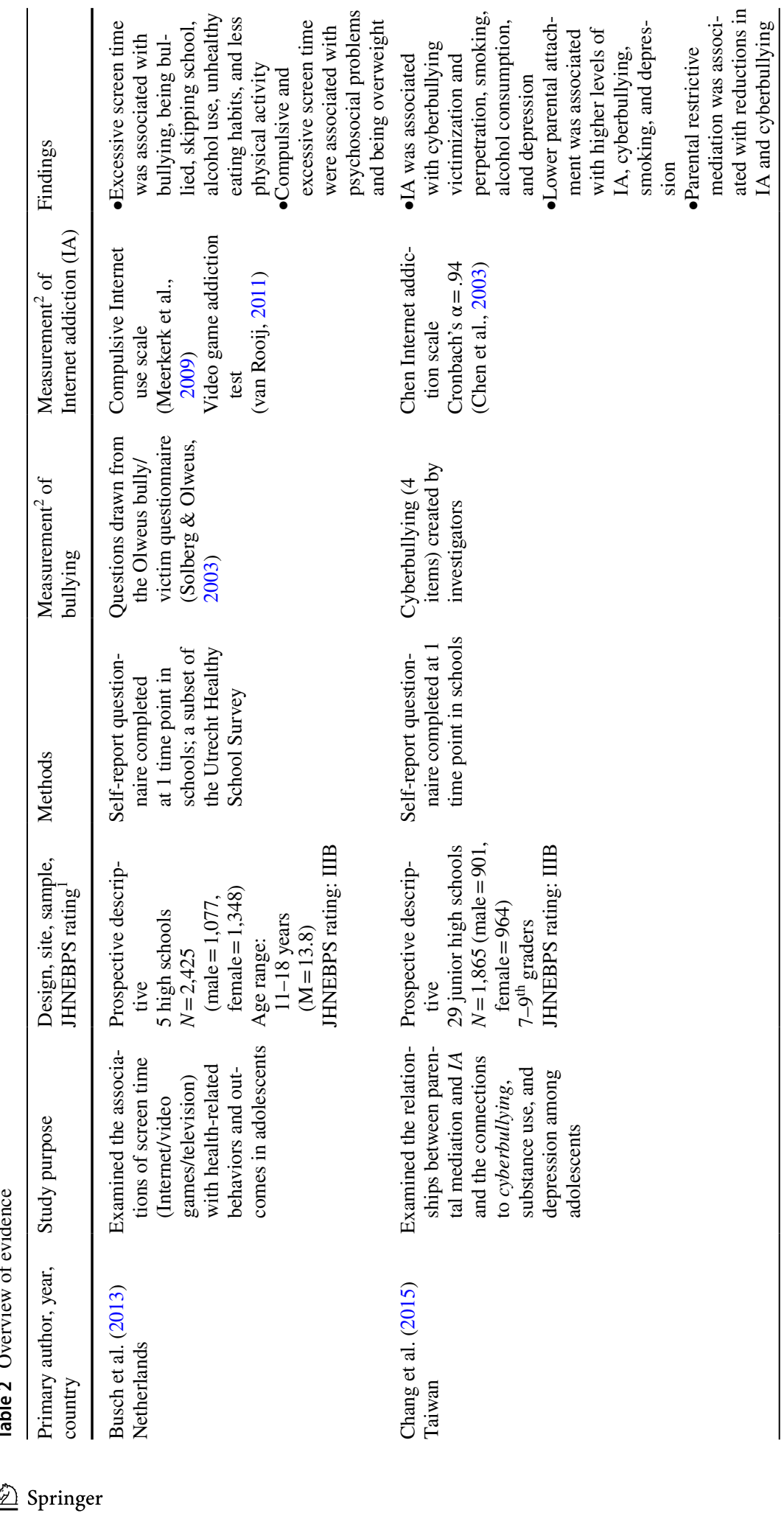




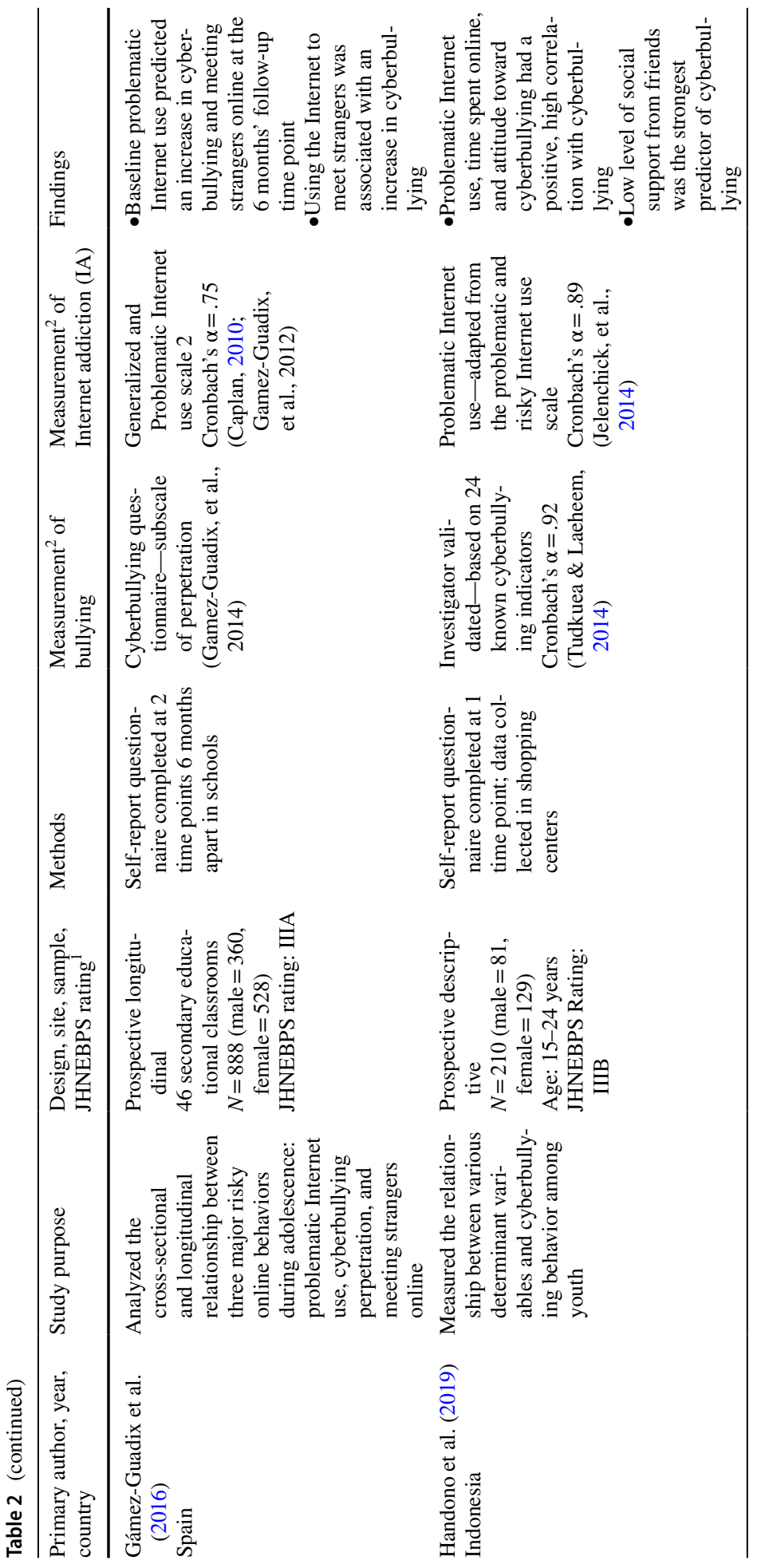




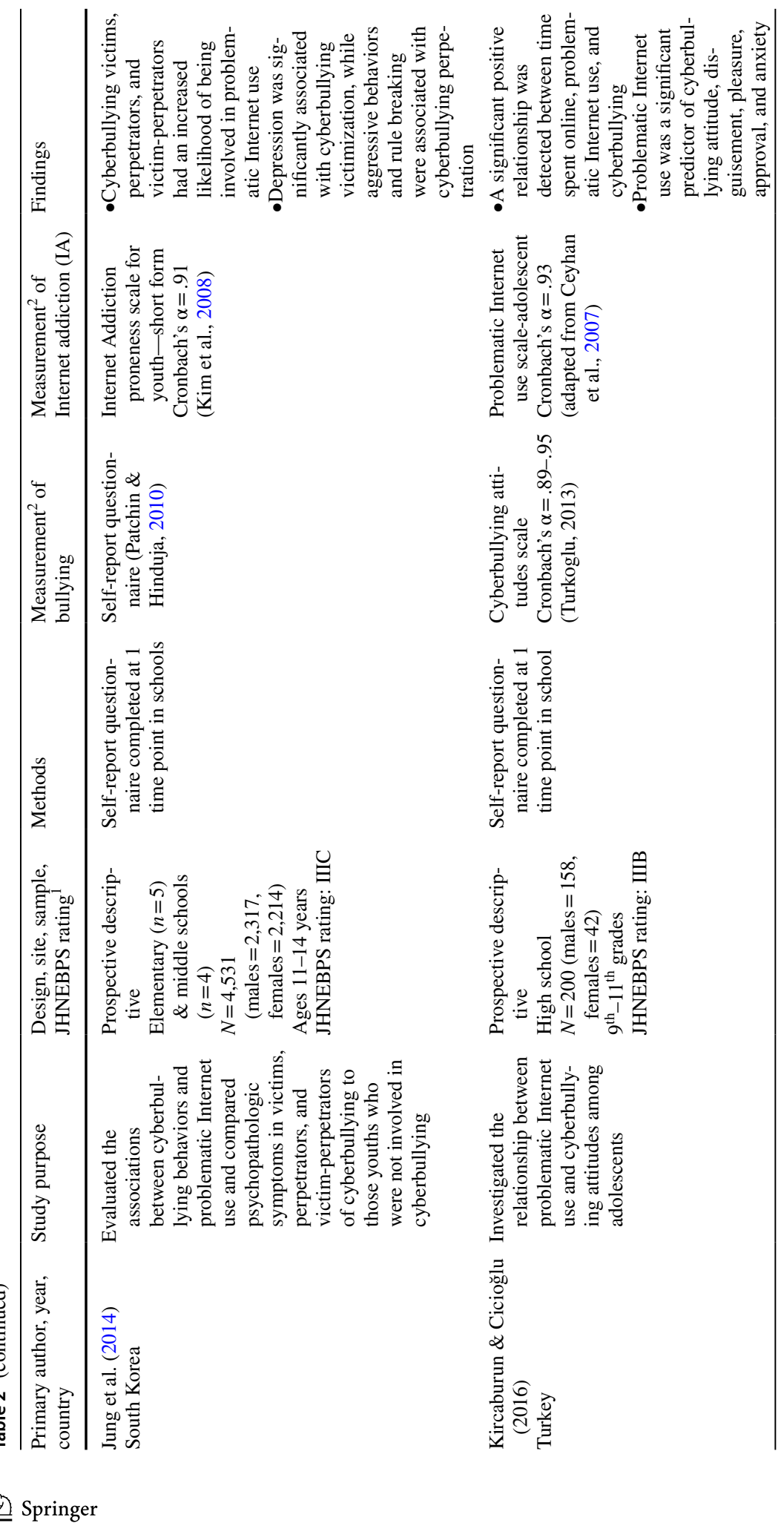




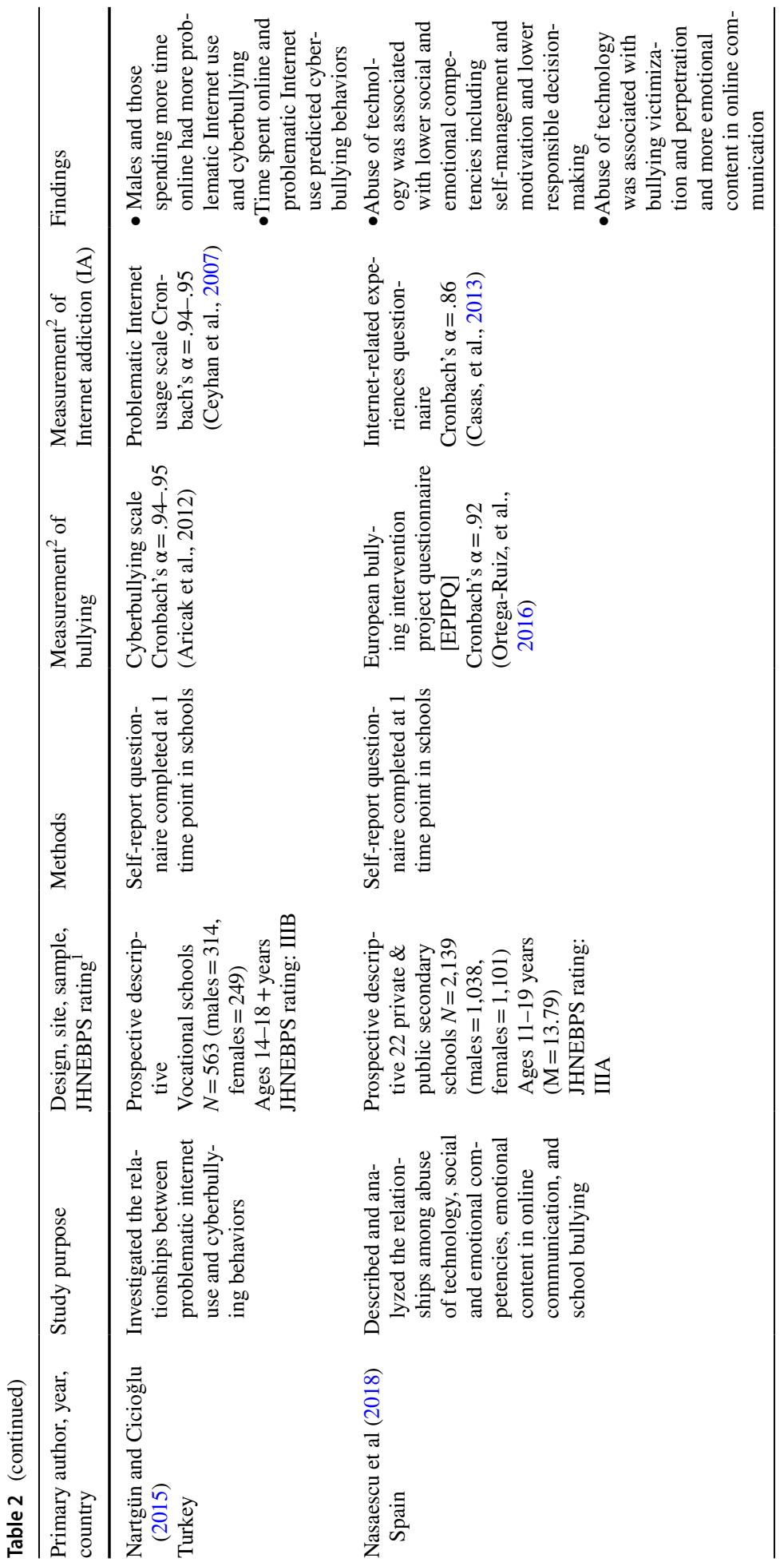




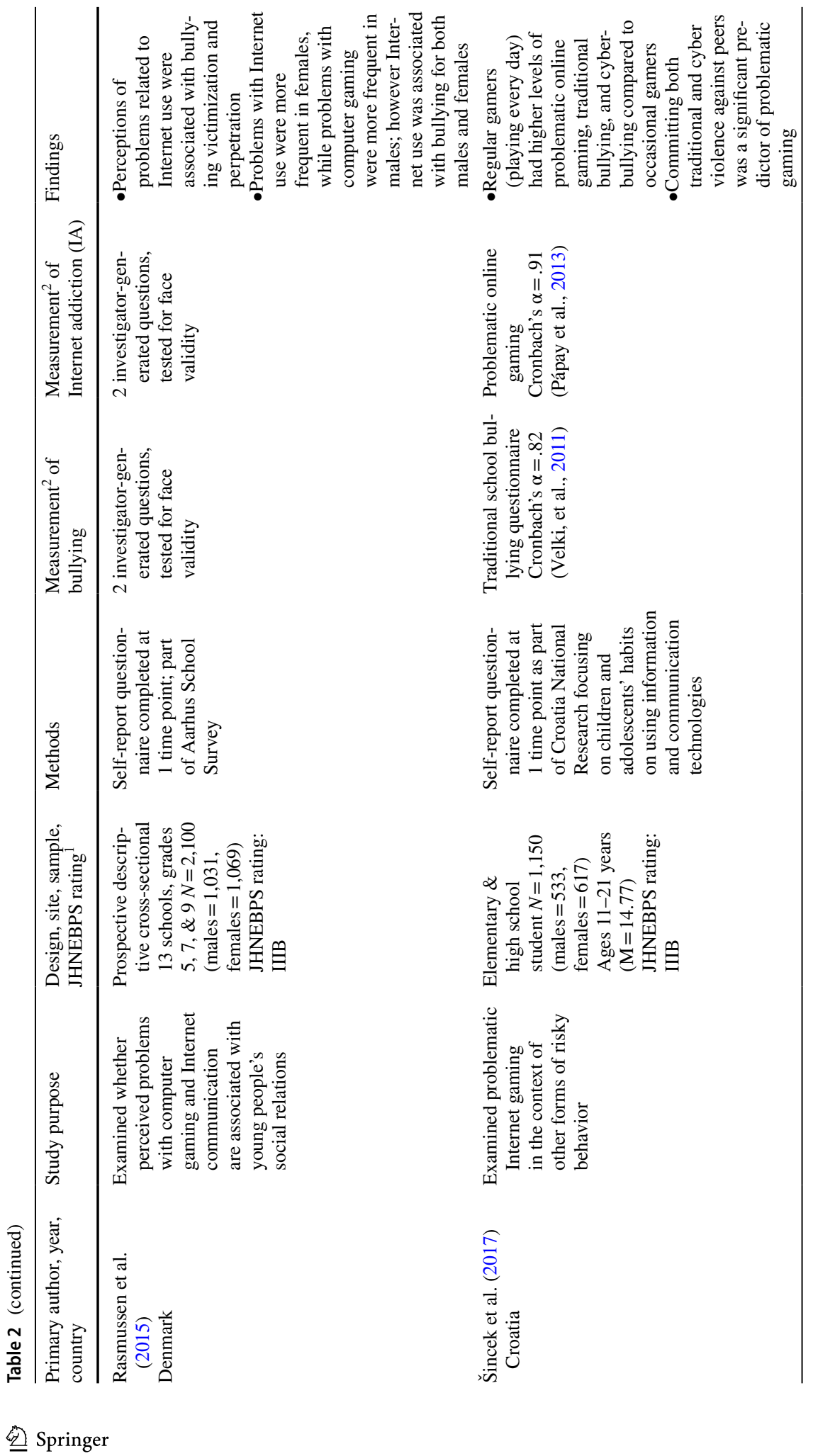




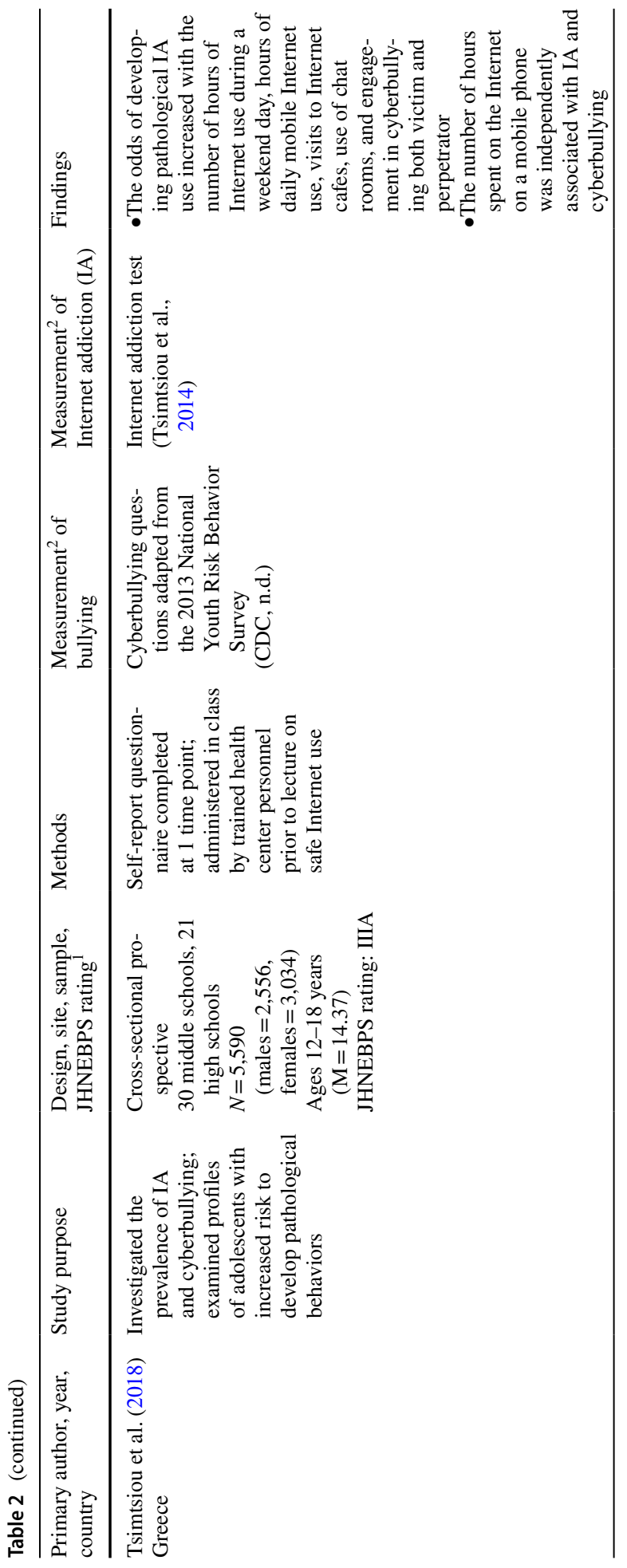




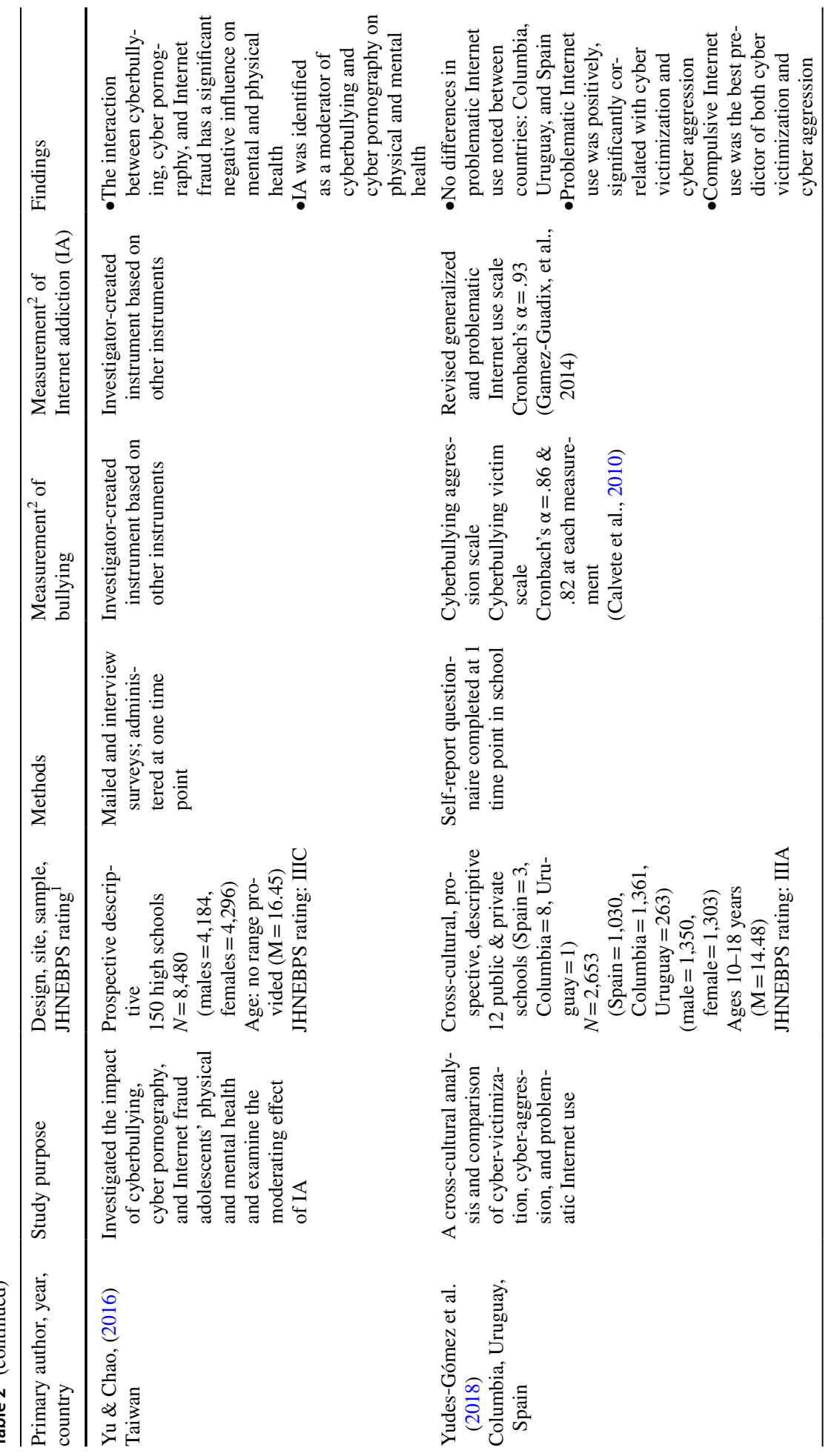




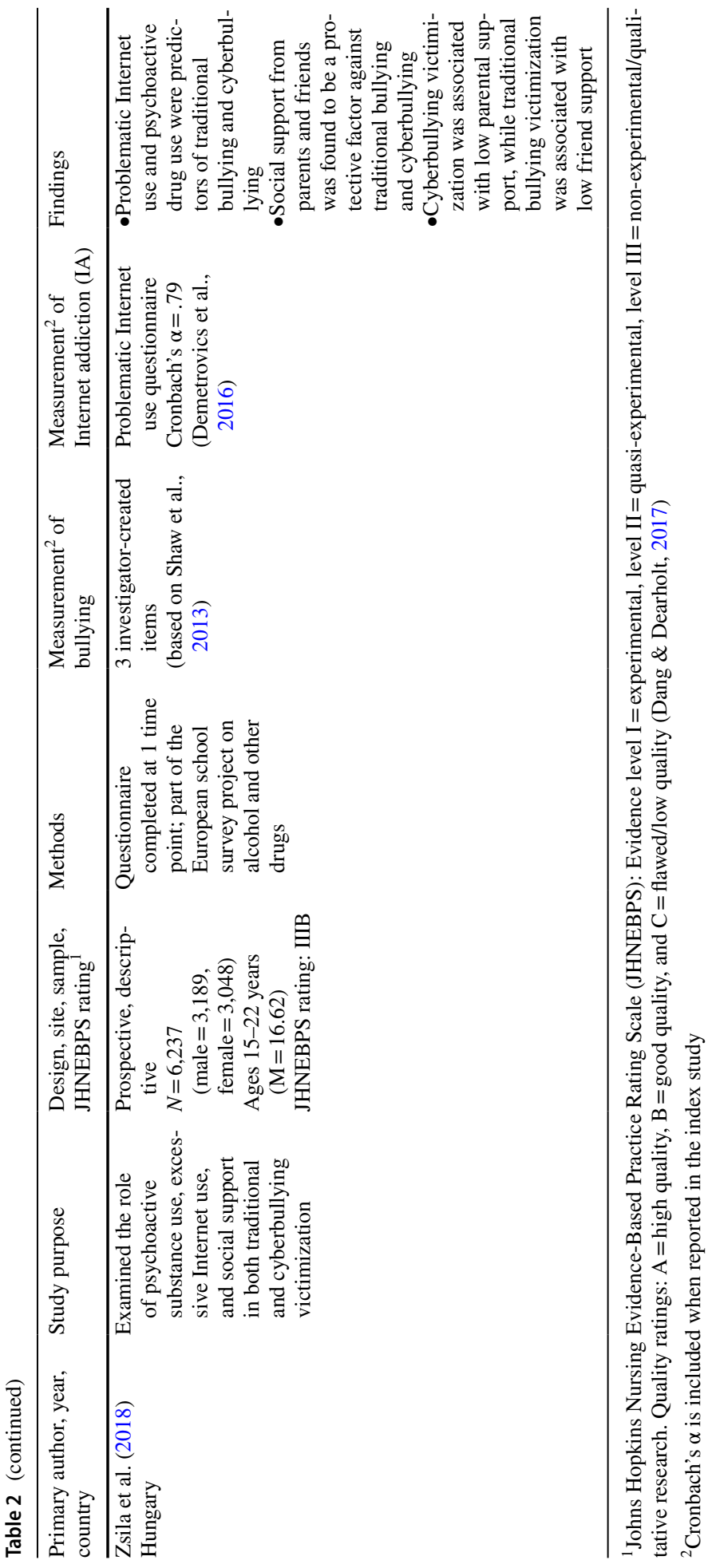


networking (Gámez-Guadix et al., 2016; Yu \& Chao, 2016; Yudes-Gómez et al., 2018; Zsila et al., 2018); compulsive video game playing (Busch et al., 2013; Rasmussen et al., 2015; Śincek et al., 2017; Tsimtsiou et al., 2018); high viewing rates of pornography/violence (Chang et al., 2015; Handono et al., 2019; Tsimtsiou et al., 2018); and excessive shopping/spending (Yu \& Chao, 2016).

Most studies did not tease out the form of IA that was associated with bullying (Chang et al., 2015; Nasaescu et al., 2018). Other studies provided a bit more information, with excessive screen time (Busch et al., 2013; Nartgün \& Cicioğlu, 2015; Tsimtsiou et al., 2018), compulsive video game playing (Busch et al., 2013; Šincek et al., 2017; Tsimtsiou et al. 2018), and high viewing rates of pornography/violence (Chang et al., 2015; Tsimtsiou et al. 2018) being the most common form of IA.

\section{Influence of Selected Demographic Variables}

In studies reporting gender differences, the co-occurrence of bullying and IA was more commonly seen in males (Chang et al., 2015; Jung et al., 2014; Nartgün \& Cicioğlu, 2015; Rasmussen et al. 2015; Šincek et al., 2017; Tsimtsiou et al., 2018). Tsimtsiou et al. (2018) reported that Greek males were more likely to be perpetrators, had a longer history of Internet usage, and viewed online pornography, while their female counterparts were more likely to be victims, older, and engaged in social media. Problematic gaming was significantly associated with both traditional and cyberbullying victimization and perpetration in males (Rasmussen et al., 2015; Šincek, et al., 2017). The impact of problematic computer gaming on bullying perpetration and victimization was seen in youths of both genders with both genders reporting having fewer friendships (Rasmussen et al. 2015).

Very little information could be culled from other key demographic constructs including age, race and ethnicity, and socio-economic status. For the three studies that examined the impact of age, the results were inconsistent. Nartgün and Cicioğlu (2015) reported no difference in youths' views on cyberbullying or problematic Internet use based on age. Higher IA in older youths was reported by Nasaescu et al. (2018), while greater problematic gaming in younger youths was reported by Šincek et al. (2017). Despite that many of countries where these studies were conducted have numerous racially and ethnically diverse subpopulations, these attributes were not explicitly addressed.

\section{Health Outcomes and Problematic Behaviors}

The interaction between cyberbullying and IA lead to poorer global physical and mental health outcomes as demonstrated through structural equation modeling in three studies (Kircaburun \& Baştuğ, 2016; Yu \& Chao, 2016; Yudes-Gómez et al., 2018). Unfortunately, many studies did examine correlations between IA and psychosocial outcomes such as low self-esteem, depression, and anxiety but did not fully model these relationships with the inclusion of bullying in their analyses (Busch et al., 2013; Chang et al., 2015; Yu \& Chao, 2016). The influence of confounding effects of the duration of screen time, diverse screen time behaviors (e.g., social networking, gaming, viewing pornography), and effect of health-related outcomes was also not clearly explicated (Busch et al., 2013; Kircaburun \& Baştuğ, 2016). Little information was available regarding the impact of physical health problems. Although some physical problems, such as poorer nutritional habits and the use of alcohol (Busch et al., 2013; Chang et al., 2015), were linked to IA, the concomitant influence of the bullying was not investigated. Zsila et al. (2018) did demonstrate that 
IA in combination with psychoactive substance use predicted bullying and cyberbullying victimization.

Low levels of social and emotional competence were related to IA and greater bullying victimization and perpetration, with a stronger relationship being reported for perpetrators than victims (Nasaescu et al., 2018; Rasmussen et al. 2015). Clusters of risky behaviors also were reported. For example, Gámez-Guadix et al. (2016) reported that problematic Internet use, cyberbullying perpetration, and meeting strangers on line were related.

\section{Role of Social Support and Parental Mediation/Supervision}

The role of parental supervision and their co-occurrence of bullying and IA in their children's lives was in evidence but not a major focus in the majority of studies reviewed. Social support and quality family relationships were significantly and negatively correlated with the co-occurrence of IA and cyberbullying when investigated (Chang et al., 2015; Handono et al., 2019). Less parental supervision was shown to place youths at higher risk for cyberbullying and IA (Chang et al., 2015).

\section{Discussion}

The purpose of this review was to explicate the relationship between youth bullying and IA. Perhaps the most striking finding in this review is that despite the vastly different cultures from which this research emanated, how similar the findings were across studies.

\section{Demographic Similarities and Differences}

Historically males were reported to engage in bullying more commonly than females; there is now some support that bullying perpetration and victimization are equalizing across genders (Olweus, 1993; Pontes et al., 2018; Smith et al., 2019). Emerging knowledge suggests that the relationships between gender roles in bullying perpetuation and victimization and their prevalence are complex, mediated by age, the rise of Internet usage, and cyberbullying and the influence of cultural norms (Casper \& Card, 2017; Smith et al., 2019).

It is not surprising that when viewed from the singular perspective of bullying, females are more vulnerable to relational bullying that occurs on social networking sites, while males are more vulnerable to bullying from gaming sites where aggression is often prominent (Casper \& Card, 2017; Smith et al., 2019). When bullying was examined through the lens of IA, however, the co-existence of these behaviors was far more common in males. While there is scant explanatory evidence, Nartgün and Cicioğlu (2015) posit that the Turkish males in their sample had more autonomy, were able to frequent cybercafes, and were relatively unsupervised allowing them to engage in IA and bullying.

Of note, no study reported participants with gender variance, those youths whose gender expression does not conform to socially defined male or female gender norms. This is a an important issue as both IA and bullying are more likely to occur in youths with nonconforming gender expression with the participants experiencing greater harm (Cooper \& Blumenfeld, 2012; DeLonga et al., 2011; Peltzer \& Pengpid, 2016; Wiederhold, 2014). It is recognized, however, in some of the countries represented across these studies that expression of gender variance is illegal or in opposition to cultural norms (Erasing 76 Crimes, 
2019). The importance of employing a socio-cultural approach in investigating the role gender plays in IA mediated bullying is highly needed.

That no clear differences in the co-existence of these behaviors by age are identified is not surprising as both behaviors are robust in adolescent populations. Failure to examine different racial and ethnic subgroups is a concern. Youths from cultural orientations different from the mainstream, especially if not politically recognized or shunned, are a high risk for bullying (Vessey, et al., 2013). Such youths may also be drawn to Internet social media and gaming sites, falsely perceiving personal anonymity and safety (Wright, 2014).

\section{Limitations: Definition and Measurement Issues}

Inconsistent definitions and instrumentation and lack of sophisticated study designs limited the synthesis of findings. The lack of clear conceptual and operational definitions for the variables of interest hindered the identification, collation, and interpretation of the data. The concept of youth IA is becoming prevalent in addiction literature, but specific diagnostic criteria remain elusive. Early measurement schemes focused on screen time, but as many youths report being online "all of the time" for academic and socialization, it is harder to determine how much screen time constitutes normative behavior. To date, the term IA or its variants are only beginning to be recognized despite 15 years of research in this area.

The WHO's International Classification of Diseases, the global standard for coding health information and causes of death, listed gaming disorder in its $11^{\text {th }}$ edition as a new diagnosis, but did not address the broader construct of IA (WHO, 2018). In other countries, including South Korea and China, video gaming is recognized as a specific diagnostic disorder, allowing treatment protocols to be developed (Parekh, 2018). The term, problematic Internet use, with specific emphasis on Internet gaming disorders, was studied for inclusion in American Psychiatric Association's Diagnostic Statistical Manual 5 (DSM) but ultimately was not included due to insufficient research (American Psychiatric Association, 2013; Petry et al., 2015). It was included in the "Emerging Measures and Models" section, an area underscoring the need for additional evidence.

The seminal definition for bullying was promulgated by Norwegian-Swedish Psychologist Olweus in 1983 as noted in this paper's introduction (Olweus, 1991). This definition has served as the benchmark for much of the bullying research worldwide despite its inherent limitations. Over time, researchers, educators, policy-makers, and non-professionals have shaped the definition of bullying to best suit their own work (Arora, 1996; Smith et al., 2002). No international standard currently exists. Recognizing the need for a uniform definition of bullying that encompasses its different modes (i.e., direct and indirect) and types (i.e., physical, verbal, relational, property damage) to be used in surveillance, research, and education, a uniform definition was released in 2014 by the US National Center for Injury Prevention and Control, Centers for Disease Control and Prevention, and Department of Education. It reads "Bullying is any unwanted aggressive behavior(s) by another youth or group of youths who are not siblings or current dating partners that involves an observed or perceived power imbalance and is repeated multiple times or is highly likely to be repeated. Bullying may inflict harm or distress on the targeted youth including physical, psychological, social, or educational harm (Gladden, et al., 2014). This definition has been widely adopted in the USA but not yet globally. The lack of operational definitions of for the two key variables - bullying and IA - has created discordance across this body of work. 
Because of the lack of conceptual clarity, the terms bullying and IA have been operationalized across the research literature using a diverse array of assessment instruments of varying quality (King et al., 2011; Vessey, et al., 2014). This was seen in the studies included in this review. Bullying was measured using seven different standardized instruments, selected questions from three different instruments, and four investigator-created measures. IA was measured using seven standardized instruments, including six variations of the Problematic Internet Use Scale, and two investigator-created measures (Table 2). For the standardized measures, their specific psychometric properties and appropriateness for the samples under investigation were rarely discussed. When psychometric properties were reported, this information is included in Table 2. Moreover, all of these instruments used self-report with its inherent issues of social desirability and likely under-reporting despite the assurance of anonymity by most investigators.

A significant limitation across these studies was that the majority used cross-sectional designs precluding the establishment of causal relationships between IA and bullying. Numerous internalizing and externalizing psychosocial problems including but not limited to anxiety and depression, suicidality, truancy, and substance use have been tied to both bullying and IA independently (Lam, 2014; Ostovar et al., 2016; Reijntjes et al., 2010, 2011). Little is known, however, as to the synergies created across bullying, IA, these diverse behaviors, and their impact on youths' health-related quality of life. Synergies created by co-occurrence of these conditions on mental health could have a more profound and enduring impact on overall health-related quality of life (Anderson et al., 2017; Klomek, et al., 2015; Takizawa et al., 2014; Zarate-Garza et al., 2017).

\section{Implications for Future Research, Practice, and Policy}

The findings of this review have underscored the need for additional research that examines the interplay that both bullying and IA have on youth mental health. Research is required that uses more rigorous prospective, longitudinal designs, and sophisticated inferential analyses across bullying, IA, and other variables of interest. Investigation of the influence of cultural and other contextual variables such as Internet literacy, accessibility, gender roles, and impact of parental involvement, on health-related quality of life is needed. Instrumentation that goes beyond self-report surveys and includes teacher and parent reports, peer nomination, and investigator observations would aid in validating these initial results. Qualitative studies would further inform these empiric findings. A fuller understanding of these relationships is foundational to the development and testing of datadriven interventions.

The high comorbidity between bullying and IA supports that formalized screening approaches for both disorders be instituted in educational, medical, and mental health settings. If problems are noted, additional screening for psychiatric disorders is warranted. Current educational programming for bullying prevention must include content of technology abuse, including appropriate expression of emotions (Nasaescu et al., 2018). Another essential component of such programming is to strengthen opportunities for parental engagement. This will allow for tailoring of interventions specifically designed for the population of interest.

Across the globe, policies and regulations for both bullying prevention and mediation and Internet usage by youths are wide-ranging and reflect national cultural mores and political agendas. While differing avenues of oversight and intervention may be implemented, 
all should acknowledge the relationship between youth bullying and IA, its consequences to youths, families, and society and implement appropriate prevention and intervention strategies.

\section{Conclusions}

The relationship between bullying and IA is firmly supported. Professionals involved with improving youths' mental health must consider the roles that bullying, IA, or its co-occurrence may play in behavioral health issues. International standardization of definitions for bullying and internet addiction will promote high-quality future qualitative and quantitative research to more fully explicate these relationships, thus allowing for the creation and testing of theory-driven interventions.

Author Contribution • Vessey, DiFazio, and Dorste conceptualized the review.

- Dorste performed the literature search.

- Vessey, DiFazio, and Neil completed the data analysis.

- Vessey, DiFazio, Neil, and Dorste drafted the manuscript.

- All members of the study team reviewed the final draft and approved submission of this manuscript.

\section{Declarations}

Ethical approval All authors agree to be accountable for all aspects of the work.

Conflict of Interest The authors declare no competing interests.

\section{References}

American Psychiatric Association. (2013). Diagnostic and statistical manual of mental disorders (DSM-5). Washington, D. C.: Author

Anderson, E. L., Steen, E., \& Stavropoulos, V. (2017). Internet use and problematic Internet use: A systematic review of longitudinal research trends in adolescence and emergent adulthood. International Journal of Adolescence and Youth, 22, 430-454. https://doi.org/10.1080/02673843.2016.1227716

Anderson, M. \& Jiang, J. (2018). Teens, social media \& technology 2018. Pew Research Center. Retrieved: https://www.file:///C:/Users/vessey/Downloads/PI_2018.05.31_TeensTech_FINAL.pdf. Accessed 25 July 2021.

Arora, C. M. (1996). Defining bullying: Towards a clearer general understanding and more effective intervention strategies. School Psychology International, 17(4), 317-329.

Bailin, A., Milanaik, R., \& Adesman, A. (2014). Health implications of new age technologies for adolescents: A review of the research. Current Opinion in Pediatrics, 26, 605-619. https://doi.org/10.1097/ MOP.0000000000000140

Beard, K. W. (2005). Internet addiction: A review of current assessment techniques and potential assessment questions. CyberPsychology \& Behavior, 8, 7-14. https://doi.org/10.1089/cpb.2005.8.7

Best, P., Manktelow, R., \& Taylor, B. (2014). Online communication, social media and adolescent wellbeing: A systematic narrative review. Children and Youth Services Review, 41, 27-36. https://doi.org/10. 1016/j.childyouth.2014.03.001

Busch, V., Ananda Manders, L., Josephus, R., \& de Leeuw, J. (2013). Screen time associated with health behaviors and outcomes in adolescents. American Journal of Health Behavior, 37, 819-830. https:// doi.org/10.5993/AJHB.37.6.11

Calvete, E., Orue, I., Estévez, A., Villardón, L., \& Padilla, P. (2010). Cyberbullying in adolescents: Modalities and aggressors' profile. Computers in Human Behavior, 26, 1128-1135. https://doi.org/10.1016/j. chb.2010.03.017 
Caplan, S. E. (2010). Theory and measurement of generalized problematic Internet use: A two-step approach. Computers in Human Behavior, 26, 1089-1097. https://doi.org/10.1016/j.chb.2010.03.012

Casas, J. A., Ruiz-Olivares, R., \& Ortega-Ruiz, R. (2013). Validation of the internet and social networking experiences questionnaire in Spanish adolescents. International Journal of Clinical and Health Psychology, 13(1), 40-48. https://doi.org/10.1016/S1697-2600(13)70006-1

Casper, D., \& Card, N. (2017). Overt and relational victimization: A meta-analytic review of their overlap and associations with social-psychological adjustment. Child Development, 88, 466-483. https://doi. org/10.1111/cdev.12621

Ceyhan, E., Ceyhan, A. A., \& Gürcan, A. (2007). The validity and reliability of the problematic Internet usage scale. Journal of Educational Science in Theory and Practice-KUYEB Journal, 7(1), 411.

Chang, F. C., Chiu, C. H., Miao, N. F., Chen, P. H., Lee, C. M., Chiang, J. T., \& Pan, Y. C. (2015). The relationship between parental mediation and Internet addiction among adolescents, and the association with cyberbullying and depression. Comprehensive Psychiatry, 57, 21-28. https://doi.org/10.1016/j. comppsych.2014.11.013

Chen, S. H., Weng, L. J., Su, Y. J., Wu, H. M., \& Yang, P. F. (2003). Development of a Chinese Internet addiction scale and its psychometric study. Chinese Journal of Psychology, 45, 279-294. https://doi. org/10.1037/t44491-000

Cooper, R. M., \& Blumenfeld, W. J. (2012). Responses to cyberbullying: A descriptive analysis of the frequency of and impact on LGBT and allied youth. Journal of LGBT Youth, 9(2), 153-177. https://doi. org/10.1080/19361653.2011.649

Dang, D., \& Dearholt, S. L. (2017). Johns Hopkins nursing evidence-based practice: Model and guidelines (3rd ed.). Sigma Theta Tau International.

DeLonga, K., Torres, H. L., Kamen, C., Evans, S. N., Lee, S., Koopman, C., \& Gore-Felton, C. (2011). Loneliness, internalized homophobia, and compulsive internet use: Factors associated with sexual risk behavior among a sample of adolescent males seeking services at a community LGBT center. Sexual Addiction \& Compulsivity, 18, 61-74. https://doi.org/10.1080/10720162.2011.581897

Demetrovics, Z., Király, O., Koronczai, B., Griffiths, M. D., Nagygyörgy, K., Elekes, Z., ... \& Urbán, R. (2016). Psychometric properties of the problematic Internet use questionnaire short-form (PIUQ-SF-6) in a nationally representative sample of adolescents. PloS One, 11, e0159409. https://doi.org/10.1371/ journal.pone.0159409

Due, P., \& Holstein, B. E. (2008). Bullying victimization among 13 to 15 year old school children: Results from two comparative studies in 66 countries and regions. International Journal of Adolescent Medicine and Health, 20, 209-222. https://doi.org/10.1515/ijamh.2008.20.2.209

Elgar, F. J., McKinnon, B., Walsh, S. D., Freeman, J., Donnelly, P. D., de Matos, M. G., ... \& Currie, C. (2015). Structural determinants of youth bullying and fighting in 79 countries. Journal of Adolescent Health, 57, 643-650. https://doi.org/10.1016/j.jadohealth.2015.08.007.

Erasing 76 Crimes (2019). Retrieved from: https://76crimes.com/76-countries-where-homosexuality-is-illeg al/. Accessed 21 July 2021.

Fegert, J. M., Vitiello, B., Plener, P. L., \& Clemens, V. (2020). Challenges and burden of the coronavirus 2019 (COVID-19) pandemic for child and adolescent mental health: A narrative review to highlight clinical and research needs in the acute phase and the long return to normality. Child and Adolescent Psychiatry and Mental Health, 14, 1-11. https://doi.org/10.1186/s13034-020-00329-3

Gámez-Guadix, M., Borrajo, E., \& Almendros, C. (2016). Risky online behaviors among adolescents: Longitudinal relations among problematic Internet use, cyberbullying perpetration, and meeting strangers online. Journal of Behavioral Addictions, 5, 100-107. https://doi.org/10.1556/2006.5.2016.013

Gámez-Guadix, M., Orue, I., Smith, P. K., \& Calvete, E. (2013). Longitudinal and reciprocal relations of cyberbullying with depression, substance use, and problematic internet use among adolescents. Journal of Adolescent Health, 53, 446-452. https://doi.org/10.1016/j.jadohealth.2013.03.030

Gámez-Guadix, M., Villa-George, F. I., \& Calvete, E. (2012). Measurement and analysis of the cognitivebehavioral model of generalized problematic Internet use among Mexican adolescents. Journal of Adolescence, 35, 1581-1591. https://doi.org/10.1016/j.adolescence.2012.06.005

Gámez-Guadix, M., Villa-George, F., \& Calvete, E. (2014). Psychometric properties of the cyberbullying questionnaire (CBQ) among Mexican adolescents. Violence and Victims, 29, 232-247. https://doi.org/ 10.1891/0886-6708.vv-d-12-00163r1

Gladden, R. M.; Vivolo-Kantor, A. M.; Hamburger, M. E.; \& Lumpkin, C. D. (2014). Bullying Surveillance among Youths: Uniform definitions for public health and recommended data elements. Version 1.0. Washington, D. C.: Centers for Disease Control and Prevention. Retrieved from: https://www.cdc.gov/ violenceprevention/pdf/bullying-definitions-final-a.pdf. Accessed 21 July 2021.

Guan, S. S. A., \& Subrahmanyam, K. (2009). Youth Internet use: Risks and opportunities. Current Opinion in Psychiatry, 22, 351-356. https://doi.org/10.1097/YCO.0b013e32832bd7e0 
Guessoum, S. B., Lachal, J., Radjack, R., Carretier, E., Minassian, S., Benoit, L., \& Moro, M. R. (2020). Adolescent psychiatric disorders during the COVID-19 pandemic and lockdown. Psychiatry research, 113264. https://doi.org/10.1016/j.psychres.2020.113264

Handono, S. G., Laeheem, K., \& Sittichai, R. (2019). Factors related with cyberbullying among the youth of Jakarta, Indonesia. Children and Youth Services Review, 99, 235-239. https://doi.org/10.1016/j.child youth.2019.02.012

Howard, J. (2017). When kids get their first cell phones around the world. CNN Health. Retrieved from: https://www.cnn.com/2017/12/11/health/cell-phones-for-kids-parenting-without-borders-expla iner-intl/index.html. Accessed 3 Aug 2021.

Influence Central (2016). Kids and tech: The evolution of today's digital natives. Retrieved from: http://influ ence-central.com/kids-tech-the-evolution-of-todays-digital-natives/. Accessed 3 Aug 2021.

Islam, N., \& Want, R. (2014). Smartphones: Past, present, and future. IEEE Pervasive Computing, 13, 89-92. https://doi.org/10.1109/MPRV.2014.74

Jain, O., Gupta, M., Satam, S., \& Panda, S. (2020). Has the COVID-19 pandemic affected the susceptibility to cyberbullying in India? Computers in Human Behavior Reports, 2, 100029. https://doi.org/10. 1016/j.chbr.2020.100029

Jelenchick, L. A., Eickhoff, J., Christakis, D. A., Brown, R. L., Zhang, C., Benson, M., \& Moreno, M. A. (2014). The problematic and risky Internet use screening scale (PRIUSS) for adolescents and young adults: Scale development and refinement. Computers in Human Behavior, 35, 171-178. https://doi. org/10.1016/j.chb.2014.01.035

Jung, Y. E., Leventhal, B., Kim, Y. S., Park, T. W., Lee, S. H., Lee, M., ... \& Park, J. I. (2014). Cyberbullying, problematic internet use, and psychopathologic symptoms among Korean youth. Yonsei Medical Journal, 55, 826-830. https://doi.org/10.3349/ymj.2014.55.3.826

Karmakar, S., \& Das, S. (2020, November). Evaluating the impact of covid-19 on cyberbullying through bayesian trend analysis. In Proceedings of the European Interdisciplinary Cybersecurity Conference (pp. 1-6).

Kim, D. I., Chung, Y. J., Lee, E. A., Kim, D. M., \& Cho, Y. M. (2008). Development of internet addiction proneness scale-short form (KS scale). Korean Journal of Counseling, 9(4), 1703-1722.

King, L. (2002). Game on: The history and culture of video games. Universe Publishing.

King, D. L., Delfabbro, P. H., Griffiths, M. D., \& Gradisar, M. (2011). Assessing clinical trials of Internet addiction treatment: A systematic review and CONSORT evaluation. Clinical Psychology Review, 31, 1110-1116. https://doi.org/10.1016/j.cpr.2011.06.009

Kircaburun, K., \& Baştuğ, I. (2016). Predicting cyberbullying tendencies of adolescents with problematic internet use. Journal of Academic Social Science Studies, 48, 385-396. https://doi.org/10.9761/JASSS 3597

Klomek, A. B., Sourander, A., \& Elonheimo, H. (2015). Bullying by peers in childhood and effects on psychopathology, suicidality, and criminality in adulthood. The Lancet Psychiatry, 2, 930-941. https://doi. org/10.1016/s2215-0366(15)00223-0

Lam, L. T. (2014). Risk factors of Internet addiction and the health effect of internet addiction on adolescents: A systematic review of longitudinal and prospective studies. Current Psychiatry Reports, 16, 508. https://doi.org/10.1007/s11920-014-0508-2

Lemish, D. (Ed.). (2013). The Routledge international handbook of children, adolescents and media. Routledge.

Lin, M. P. (2020). Prevalence of internet addiction during the covid-19 outbreak and its risk factors among junior high school students in Taiwan. International Journal of Environmental Research and Public Health, 17(22), 8547. https://doi.org/10.3390/ijerph17228547

Livingstone, S., Stoilova, M., \& Kelly, A. (2016). Cyberbullying: Incidence, trends and consequences. London, UK: London School of Economics. Retrieved from: http://eprints.lse.ac.uk/68079/1/Livingstone_ Cyberbullying\%20incidence\%20trends_2016.pdf. Accessed 23 May 2021.

Mascheroni, G., \& Ólafsson, K. (2016). The mobile Internet: Access, use, opportunities and divides among European children. New Media \& Society, 18, 1657-1679. https://doi.org/10.1177/1461444814567986

Mak, K. K., Lai, C. M., Watanabe, H., Kim, D. I., Bahar, N., Ramos, M., ... \& Cheng, C. (2014). Epidemiology of internet behaviors and addiction among adolescents in six Asian countries. Cyberpsychology, Behavior, and Social Networking, 17, 720-728. https://doi.org/10.1089/cyber.2014.0139

Meerkerk, G. J., Van Den Eijnden, R. J., Vermulst, A. A., \& Garretsen, H. F. (2009). The compulsive internet use scale (CIUS): Some psychometric properties. Cyberpsychology \& Behavior, 12, 1-6. https:// doi.org/10.1089/cpb.2008.0181

Modecki, K. L., Minchin, J., Harbaugh, A. G., Guerra, N. G., \& Runions, K. C. (2014). Bullying prevalence across contexts: A meta-analysis measuring cyber and traditional bullying. Journal of Adolescent Health, 55, 602-611. https://doi.org/10.1016/j.jadohealth.2014.06.007 
Moher, D., Liberati, A., Tetzlaff, J., Altman, D. G., \& Group, T. P. (2009). Preferred reporting items for systematic reviews and meta-analyses: The PRISMA statement. PLoS Medicine, 6, e1000097. https://doi. org/10.1371/journal.pmed.1000097

Monks, C. P., \& Coyne, I. (2011). A history of research into bullying. In C. P. Monks \& I. Coyne (Eds.), Bullying in different contexts (pp. 1-11). Cambridge University Press.

Nartgün, Ş. S., \& Cicioğlu, M. (2015). Problematic Internet use and cyberbullying in vocational school students. International Online Journal of Educational Sciences, 7, 10-26. https://doi.org/10.15345/iojes. 2015.03.018

Nasaescu, E., Marín-López, I., Llorent, V. J., Ortega-Ruiz, R., \& Zych, I. (2018). Abuse of technology in adolescence and its relation to social and emotional competencies, emotions in online communication, and bullying. Computers in Human Behavior, 88, 114-120. https://doi.org/10.1016/j.chb.2018.06.036

Olweus, D. (1991). Bully/victim problems among schoolchildren: Basic facts and effects of a school based intervention program. The Development and Treatment of Childhood Aggression, 17, 411-448.

Olweus, D. (1993). Understanding children's worlds. Bullying at school: What we know and what we can do. Blackwell Publishing.

Ortega-Ruiz, R., Del Rey, R., \& Casas, J. A. (2016). Evaluar el bullying y el cyberbullying validación española del EBIP-Q y del ECIP-Q. Psicología Educativa, 22, 71-79. https://doi.org/10.1016/j.pse.2016. 01.004

Ostovar, S., Allahyar, N., Aminpoor, H., Moafian, F., Nor, M. B. M., \& Griffiths, M. D. (2016). Internet addiction and its psychosocial risks (depression, anxiety, stress and loneliness) among Iranian adolescents and young adults: A structural equation model in a cross-sectional study. International Journal of Mental Health and Addiction, 14(3), 257-267.

Pápay, O., Urbán, R., Griffiths, M. D., Nagygyörgy, K., Farkas, J., Kökönyei, G., ... \& Demetrovics, Z. (2013). Psychometric properties of the problematic online gaming questionnaire short-form and prevalence of problematic online gaming in a national sample of adolescents. Cyberpsychology, Behavior, and Social Networking, 16, 340-348. https://doi.org/10.1089/cyber.2012.0484

Parekh, R. (2018). Internet gaming. Retrieved from: https:/www.psychiatry.org/patients-families/internetgaming. Accessed 18 May 2021.

Patchin, J. W., \& Hinduja, S. (2010). Cyberbullying and self-esteem. Journal of School Health, 80, 614621. https://doi.org/10.1111/j.1746-1561.2010.00548.x

Peltzer, K., \& Pengpid, S. (2016). Minority stress among lesbian, gay, bisexual, and transgender (LGBT) university students in ASEAN countries: Associations with poor mental health and addictive behavior. Gender and Behaviour, 14(3), 7806-7815.

Petry, N. M., Rehbein, F., Ko, C. H., \& O'Brien, C. P. (2015). Internet gaming disorder in the DSM-5. Current Psychiatry Reports, 17, 72. https://doi.org/10.1007/s11920-015-0610-0

Pontes, N. M., Ayres, C. G., Lewandowski, C., \& Pontes, M. C. (2018). Trends in bullying victimization by gender among US high school students. Research in Nursing \& Health, 41, 243-251. https://doi.org/ 10.1002/nur.21868

Rasmussen, M., Meilstrup, C. R., Bendtsen, P., Pedersen, T. P., Nielsen, L., Madsen, K. R., \& Holstein, B. E. (2015). Perceived problems with computer gaming and Internet use are associated with poorer social relations in adolescence. International Journal of Public Health, 60, 179-188. https://doi.org/ 10.1007/s00038-014-0633-z

Reijntjes, A., Kamphuis, J. H., Prinzie, P., \& Telch, M. J. (2010). Peer victimization and internalizing problems in children: A meta-analysis of longitudinal studies. Child Abuse \& Neglect, 34, 244-252. https:// doi.org/10.1016/j.chiabu.2009.07.009

Reijntjes, A., Kamphuis, J. H., Prinzie, P., Boelen, P. A., Van der Schoot, M., \& Telch, M. J. (2011). Prospective linkages between peer victimization and externalizing problems in children: A meta-analysis. Aggressive Behavior, 37, 215-222. https://doi.org/10.1002/ab.20374

Richards, D., Caldwell, P. H., \& Go, H. (2015). Impact of social media on the health of children and young people. Journal of Paediatrics and Child Health, 51, 1152-1157. https://doi.org/10.1111/jpc.13023

Shapiro, L. A. S., \& Margolin, G. (2014). Growing up wired: Social networking sites and adolescent psychosocial development. Clinical Child and Family Psychology Review, 17, 1-18. https://doi.org/10. 1007/s10567-013-0135-1

Shaw, T., Dooley, J. J., Cross, D., Zubrick, S. R., \& Waters, S. (2013). The forms of bullying scale (FBS): Validity and reliability estimates for a measure of bullying victimization and perpetration in adolescence. Psychological Assessment, 25, 1045. https://doi.org/10.1037/a0032955

Šincek, D., Humer, J. T., \& Duvnjak, I. (2017). Correlates of problematic gaming-is there support for proneness to risky behaviour? Psychiatria Danubina, 29, 302-312. https://doi.org/10.24869/psyd. 2017.302 
Smith, P. K., Cowie, H., Olafsson, R. F., \& Liefooghe, A. P. (2002). Definitions of bullying: A comparison of terms used, and age and gender differences, in a Fourteen-Country international comparison. Child Development, 73, 1119-1133. https://doi.org/10.1111/1467-8624.00461

Smith, P. K., López-Castro, L., Robinson, S., \& Görzig, A. (2019). Consistency of gender differences in bullying in cross-cultural surveys. Aggression and Violent Behavior, 45, 33-40. https://doi.org/10.1016/j. avb.2018.04.006

Solberg, M. E., \& Olweus, D. (2003). Prevalence estimation of school bullying with the Olweus bully/victim questionnaire. Aggressive Behavior: Official Journal of the International Society for Research on Aggression, 29, 239-268. https://doi.org/10.1002/ab.10047

Srabstein, J. C., \& Leventhal, B. L. (2010). Prevention of bullying-related morbidity and mortality: A call for public health policies. Bulletin of the World Health Organization, 88, 403-404. https://doi.org/10. 2471/BLT.10.077123

Statistica (2019). Length of time that teen internet users in the United States think they could go without their smartphone as of May 2017, by gender. Retrieved from: https://www.statista.com/statistics/ 745439/us-teen-internet-users-length-of-time-without-smartphone-use/. Accessed 18 May 2021.

Paschke, K., Austermann, M. I., Simon-Kutscher, K., \& Thomasius, R. (2021, ahead of print). Adolescent gaming and social media usage before and during the COVID-19 pandemic. Sucht, 67(1). https://doi. org/10.1024/0939-5911/a000694

Takizawa, R., Maughan, B., \& Arseneault, L. (2014). Adult health outcomes of childhood bullying victimization: Evidence from a five-decade longitudinal British birth cohort. American Journal of Psychiatry, 171, 777-784. https://doi.org/10.1176/appi.ajp.2014.13101401

Tsimtsiou, Z., Haidich, A. B., Kokkali, S., Dardavesis, T., Young, K. S., \& Arvanitidou, M. (2014). Greek version of the Internet addiction test: A validation study. Psychiatric Quarterly, 85, 187-195. https:// doi.org/10.1007/s11126-013-9282-2

Tsimtsiou, Z., Haidich, A. B., Drontsos, A., Dantsi, F., Sekeri, Z., Drosos, E., ... \& Arvanitidou, M. (2018). Pathological Internet use, cyberbullying and mobile phone use in adolescence: a school-based study in Greece. International Journal of Adolescent Medicine and Health, 30, 1-9. https://doi.org/10.1515/ ijamh-2016-0115

Tudkuea, T., \& Laeheem, K. (2014). Development of indicators of cyberbullying among youths in Songkhla Province. Asian Social Science, 10, 74. https://doi.org/10.5539/ass.v10n14p74

Türkoğlu, S. (2013). Examination of the relationship between the problematic internet use and cyberbullying tendencies of the adolescents. (unpublished Masters Thesis). Marmara University Institute of Educational Science.

U.S. Centers for Disease Control and Prevention. (2018). Youth risk behavior survey: Data summary and trends report: 2007-2017. Atlanta, GA: Author. Retrieved from: https://www.cdc.gov/healthyyouth/ data/yrbs/pdf/trendsreport.pdf. Accessed: 28 April 2021.

Van Dijck, J. (2013). The culture of connectivity: A critical history of social media. Oxford University Press.

Van Rooij, A. J. (2011). Online video game addiction. Exploring a new phenomenon [PhD Thesis]. Rotterdam, The Netherlands: Erasmus University Rotterdam

Velki, T., Kuterovac Jagodić, G., \& Vrdoljak, G. (2011). Razvoj upitnika o nasilju među školskom djecom. Neobjavljen rad.

Vessey, J. A., DiFazio, R. L., \& Strout, T. D. (2013). Youth bullying: A review of the science and call to action. Nursing Outlook, 61, 347-345. https://doi.org/10.1016/j.outlook.2013.04.011

Vessey, J. A., Strout, T. D., DiFazio, R. L., \& Walker, A. (2014). Measuring the youth bullying experience: A systematic review of the psychometric properties of available instruments. Journal of School Health, 84, 819-843. https://doi.org/10.1111/josh.12210

Wallace, P. (2014). Internet addiction disorder and youth: There are growing concerns about compulsive online activity and that this could impede students' performance and social lives. EMBO Reports, 15, 12-16. https://doi.org/10.1002/embr.201338222

Wiederhold, B. K. (2014). Cyberbullying and LGBTQ youth: A deadly combination. Cyberpsychology, Behavior, and Social Networking, 17, 569-570. https://doi.org/10.1089/cyber.2014.1521

World Health Organization (2018). International classification of diseases, $11 \mathrm{ed}$. Retrieved from: https:// icd.who.int/en. Accessed 27 May 2021.

World Health Organization: Regional Office for Europe (2012). Health behavior in school-aged children (HBSC) study: International report from the 2009-2010 survey. Social Determinants of Health and Well Being among Young People. Retrieved from http://www.euro.who.int/_data/assets/pdf_file/0003/ 163857/Social-determinants-of-healthand-well-being-among-young-people.pdf. Accessed Accessed 9 May 2021. 
Wright, M. F. (2014). Predictors of anonymous cyber aggression: The role of adolescents' beliefs about anonymity, aggression, and the permanency of digital content. Cyberpsychology, Behavior, and Social Networking, 17, 431-438. https://doi.org/10.1089/cyber.2013.0457

Yu, T. K., \& Chao, C. M. (2016). Internet misconduct impact adolescent mental health in Taiwan: The moderating roles of internet addiction. International Journal of Mental Health and Addiction, 14, 921-936. https://doi.org/10.1007/s11469-016-9641-y

Yudes-Gómez, C., Baridon-Chauvie, D., \& González-Cabrera, J. M. (2018). Cyberbullying and problematic Internet use in Colombia, Uruguay and Spain: Cross-cultural study. Comunicar. Media Education Research Journal, 26, 49-58. https://doi.org/10.3916/c56-2018-05

Zarate-Garza, P. P., Biggs, B. K., Croarkin, P., Morath, B., Leffler, J., Cuellar-Barboza, A., \& Tye, S. J. (2017). How well do we understand the long-term health implications of childhood bullying. Harvard Review of Psychiatry, 25, 89-95. https://doi.org/10.1097/HRP.0000000000000137

Zsila, Á., Orosz, G., Király, O., Urbán, R., Ujhelyi, A., Jármi, É., ... \& Demetrovics, Z. (2018). Psychoactive substance use and problematic internet use as predictors of bullying and cyberbullying victimization. International Journal of Mental Health and Addiction, 16, 466-479. https://doi.org/10.1007/ s11469-017-9809-0

Publisher's Note Springer Nature remains neutral with regard to jurisdictional claims in published maps and institutional affiliations. 